\title{
Analysis of Chlorogenic Acid Oxidation Pathway in Simulated Enzymatic Honeysuckle Browning System by High Performance Liquid Chromatography and Mass Spectrometry
}

\author{
Lei Luo*, Yingchao Hao, Li Jia and Wenxue Zhu \\ College of Food and Bioengineering, Henan University of Science and Technology, Luoyang, 471023, Henan, China
}

*For correspondence: Email: 13623896431@139.com; Tel:13623896431

Revised accepted: 3 January 2016

\begin{abstract}
Purpose: To investigate the pathways involved in the oxidation of chlorogenic acid (CA) and phenol metabolism in honeysuckle buds.

Methods: A model that mimics CA oxidation by honeysuckle polyphenol oxidase (PPO) by controlling the reaction temperature or reaction duration was employed, and the resulting products were analyzed by high-performance liquid chromatography followed by mass spectrometry (LC-MS).

Results: The pathway of CA oxidation by PPO in honeysuckle involves CA, hydroxyl - CA, CA-oquinone derivatives, and CA-p-quinone derivatives.

Conclusion: $C A$ oxidation and the enzymatic browning reaction significantly impact the quality of honeysuckle and other fresh agricultural products.
\end{abstract}

Keywords: Honeysuckle, Chlorogenic acid, Enzymatic browning, Mimic system, Oxidation pathway, High-performance liquid chromatography-mass spectrometry

Tropical Journal of Pharmaceutical Research is indexed by Science Citation Index (SciSearch), Scopus, International Pharmaceutical Abstract, Chemical Abstracts, Embase, Index Copernicus, EBSCO, African Index Medicus, JournalSeek, Journal Citation Reports/Science Edition, Directory of Open Access Journals (DOAJ), African Journal Online, Bioline International, Open-J-Gate and Pharmacy Abstracts

\section{INTRODUCTION}

Honeysuckle, which is the flower bud of the Caprifoliaceae plant (Caprifoliaceae Ionicera L.), is an edible natural substance [1] with medicinal properties used in traditional Chinese herbal medicine. Because it possesses a variety of biological activities, honeysuckle is widely used in pharmaceuticals, beverages, health foods, and other products. One of the major bioactive components of honeysuckle is chlorogenic acid $(\mathrm{CA})$.

Phenolic compounds in plant-based foods are important factors that contribute to enzymatic browning, a process that commonly occurs in fresh plant-based foods. There are many phenolics that induce browning [2], but CA is one of the most common. The widely accepted mechanisms that cause browning include mechanical damage (e.g., peeling, cutting, bruising, insect bites, or pulping) or abnormal environmental conditions (e.g., frostbite or heating) that destroy the redox balance in fruit or vegetable tissues and lead to the accumulation of oxidation products, color changes [3], and severe reductions in commercial and nutritional value. The water content of fresh honeysuckle is approximately $80 \%$, which renders the flower unsuitable for transport and storage. In order to ensure the quality of honeysuckle buds and to prevent the deterioration of color and the 
accumulation of bioactive components [4-6], immediate drying is required prior to preservation.

In a prior study, Hou [7] demonstrated that enzymatic oxidation of CA is the major cause of the browning reaction in honeysuckle buds. Additionally, Robards et al [8] revealed that differences in the generation of quinones induced by enzymatic and non-enzymatic browning are a result of the rate of enzymatic browning, which occurs much faster than non-enzymatic browning. Accordingly, the purpose of this study was to establish an enzymatic system of honeysuckle polyphenol oxidase (PPO) and to evaluate the CA oxidation pathway in honeysuckle.

\section{EXPERIMENTAL}

\section{Reagents}

The analytical reagents used to prepare the PPO included analytical grade phosphoric acid, alcohol, phenylthiourea, ammonium sulfate, disodium hydrogen phosphate, and sodium dihydrogen phosphate. Chromatographically pure acetonitrile and methanol were used as the mobile phases for high-performance liquid chromatography (HPLC). Chlorogenic acid was purchased from the National Institutes and was used as the food and drug control (Beijing, China).

\section{Plant materials}

Fresh Jinfeng I honeysuckle (Caprifoliaceae lonicera L.) buds were harvested in Fengqiu County, China. The buds were picked once per month from July to September 2012. The plants were authenticated by Weiping Yin, president of the College of Chemical Industry and Pharmaceutical at Henan University of Science and Technology in June 2012.

\section{Preparation of PPO from honeysuckle buds}

Fresh honeysuckle buds were screened for pests and washed with distilled water. After drying, the juice from the honeysuckle buds was weighed and mixed with $0.05 \mathrm{~mol} / \mathrm{L}$ phosphate buffer $(\mathrm{pH}$ $6.5)$ containing $4 \%$ polyvinylpyrrolidone (PVP) at a 1: $4(\mathrm{~W} / \mathrm{r})$ ratio to obtain honeysuckle bud homogenate. The homogenate was then extracted with methyl alcohol for $24 \mathrm{~h}$ at $4{ }^{\circ} \mathrm{C}$, filtered at $4{ }^{\circ} \mathrm{C}$, and centrifuged for 30 mins at $12,000 \mathrm{rpm}$. The supernatant was collected as the crude extract. To obtain $95 \%$ saturation, the extract was centrifuged at $12,000 \mathrm{rpm}$ for $30 \mathrm{~min}$ at $4{ }^{\circ} \mathrm{C}$. The precipitate was dissolved in $5 \mathrm{~mL}$ of $10 \mathrm{mM}$ phosphate buffer $(\mathrm{pH} 6.5)$ and dialyzed against the same buffer for $24 \mathrm{~h}$ at $4{ }^{\circ} \mathrm{C}$ [9-11]. The dialyzed sample was used in the experiments.

\section{Preparation of enzymatically-oxidized products in the mimic system}

In this study, CA was selected as the phenolic material standard. The $\mathrm{pH}$ of the reactions was adjusted to 6.83 , and the concentration of the CA was $200 \mathrm{mg} / \mathrm{L}$. The ratio of PPO to phenolic substances was 1:2. The enzymatic oxidation reactions were conducted at $0{ }^{\circ} \mathrm{C}$ for $0,0.5,1$, 10 , and $35 \mathrm{~min}$ (as the enzymatic oxidation system I of CA). Reactions were also performed for $1 \mathrm{~h}$ at $0,20,40,60$ and $80{ }^{\circ} \mathrm{C}$ (as the enzymatic oxidation system II of CA).

\section{Preparation of non-enzymatic oxidation products in the mimic system}

The non-enzymatic oxidation reaction was conducted at $\mathrm{pH} 6.83$ in the presence of 200 $\mathrm{mg} / \mathrm{L} \mathrm{CA}$ for $1 \mathrm{~h}$ at $40^{\circ} \mathrm{C}$.

\section{HPLC analysis of oxidation products in the mimic system}

After completion of the mimic reaction, methanol was added to the reaction system to a final concentration of $50 \%$, and extraction was conducted in a water bath for $1.5 \mathrm{~h}$ at $70{ }^{\circ} \mathrm{C}$. Prior to HPLC analysis, particulates were removed by filtering the extract through a 0.45 $\mu \mathrm{m}$ membrane. For analysis, $0.5 \mu \mathrm{L}$ of the extract was injected into a BEH C18 analytical column $(2.1 \mathrm{~mm} \times 100 \mathrm{~mm}, 1.7 \mu \mathrm{m})$. The mobile phases consisted of acetonitrile (A) and $0.1 \%$ formic acid (B). The extracts were eluted with the following gradient: $5-40 \% \mathrm{~A}$ for $0-20 \mathrm{~min}$ and $40-90 \% \mathrm{~A}$ for $20-25 \mathrm{~min}$ at a flow rate of 0.3 $\mathrm{mL} / \mathrm{min}$. The column temperature was $45^{\circ} \mathrm{C}$ and the detection wavelength was $327 \mathrm{~nm}$. CA was used as the internal standard. Under each reaction condition, the components of the oxidation products were compared and analyzed by mass spectrometry.

\section{Analysis of significantly changed products in the mimic system}

For analysis, $0.5 \mu \mathrm{L}$ of the extract was injected into a BEH C18 analytical column $(2.1 \mathrm{~mm} \times 100$ $\mathrm{mm}, 1.7 \mu \mathrm{m}$ ). The column temperature was 45 ${ }^{\circ} \mathrm{C}$ and the mobile phases consisted of acetonitrile (A) and $0.1 \%$ formic acid (B). The extracts were eluted with the following gradient: $5-40 \% \mathrm{~A}$ for $0-20$ min and $40-90 \% \mathrm{~A}$ in $20-25$ 
min at a flow rate of $0.3 \mathrm{~mL} / \mathrm{min}$. All extracts were analyzed by electrospray ionization $(\mathrm{ESI})$ by applying a $3.5 \mathrm{kV}$ capillary voltage within the ion source. The cone voltage was $20 / 40 \mathrm{~V}$, the ion source temperature was $100{ }^{\circ} \mathrm{C}$, and the desolution temperature was $400{ }^{\circ} \mathrm{C}$. The flow rate of the de-solution gas was $500 \mathrm{~L} / \mathrm{h}$ and the flow rate of the cone gas was $50 \mathrm{~L} / \mathrm{h}$. The MS survey scan range was $100-1500 \mathrm{~m} / \mathrm{z}$, the collision energy was $6 \mathrm{~V}$, and the detector voltage was $1600 \mathrm{~V}$.

\section{Data analysis}

The data resulting from the preparation of PPO were analyzed using Design-Expert $\circledast$ software (v. 8.0.6). $P<0.05$ was considered statistically significant. The data from HPLC and mass spectrometry experiments were analyzed using Waters MassLynx TM (v. 4.1) MS software.

\section{RESULTS}

\section{The CA enzymatic oxidation process at various reaction times}

The results revealed the status of each of the reaction substances during the oxidation of $\mathrm{CA}$ by PPO at the initial time point $(0 \mathrm{~min})$. Due to the extended reaction duration, obvious changes were detected in the reaction substances over time. All of the chromatographic peaks were numbered, and the peak areas at different retention times were compared after omitting peaks with no apparent changes and generating a curve that described the change in peak areas (Figure 1).

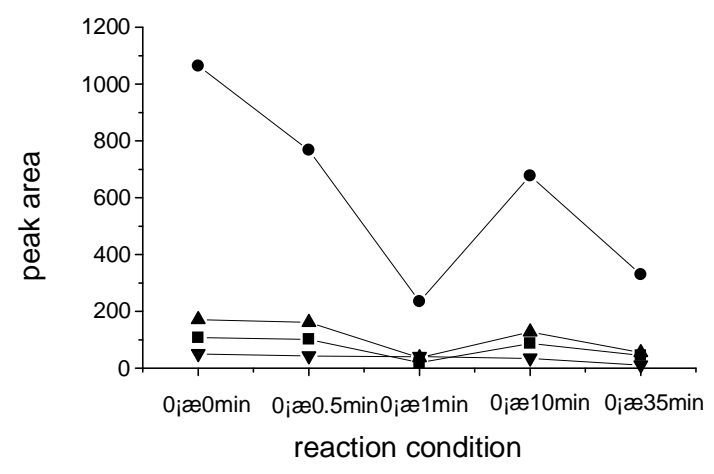

Figure 1: Analysis of $C A$ enzymatic oxidation in the mimic system I. Key: $\mathbf{\square}=$ peak $2 ; \bullet=$ peak $5(\mathrm{CA}) ; \boldsymbol{\Lambda}$ $=$ peak $7 ; \boldsymbol{\nabla}=$ peak 8

Figure 1 shows changes in the concentration of the reaction substances during the $\mathrm{CA}$ mimic enzymatic oxidation reaction at $0{ }^{\circ} \mathrm{C}$ after $35 \mathrm{~min}$.
Although the areas for peaks 2, 5, and 7 were larger at $10 \mathrm{~min}$ than the corresponding peak areas at $1 \mathrm{~min}$, a gradual trend indicating the reduction in total reaction substances was observed over the course of the 35 min reaction.

\section{Enzymatic oxidation of CA at various temperatures}

The results demonstrated the catalytic oxidation of $\mathrm{CA}$ in $1 \mathrm{~h}$ at $0,20,40,60$, and $80^{\circ} \mathrm{C}$. All of the chromatographic peaks were numbered and compared. A curve describing the obvious changes in the peak areas is shown in Figure 2.

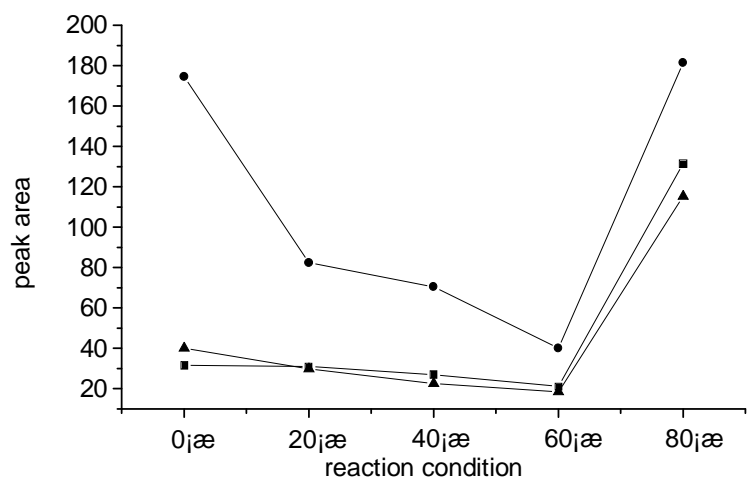

Figure 2: Analysis of $\mathrm{CA}$ enzymatic oxidation in mimic system II. Note: $\boldsymbol{\Xi}=$ peak $2 ; \bullet=$ peak $5(\mathrm{CA})$; $\Delta=$ peak 7

Exploration of the CA enzymatic oxidation pathway revealed that the PPO activity at low and high temperatures $\left(0\right.$ and $80{ }^{\circ} \mathrm{C}$, respectively) was inhibited, whereas the enzymatic oxidation reaction at $40{ }^{\circ} \mathrm{C}$ was the strongest and thus the analysis of the CA oxidation products generated at this temperature was more difficult (Figure 2). In order to facilitate the control of CA oxidation products at each stage, the enzymatic oxidation of CA in the mimic system was held constant at $0{ }^{\circ} \mathrm{C}$.

Figure 2 reveals comparable trends in the peak areas of the three substances represented by peaks 2, 5, and 7, which suggested that these substances were similar to $\mathrm{CA}$ and had a consistent reaction pathway in the reaction system. Following the HPLC analysis of the products of the CA enzymatic oxidation process after various reaction durations, the substances from peaks 2, 5, and 7 were believed to be phenolic acids.

\section{Enzymatic oxidation pathway for CA}

The total ion current chromatograms for peaks 2 , 


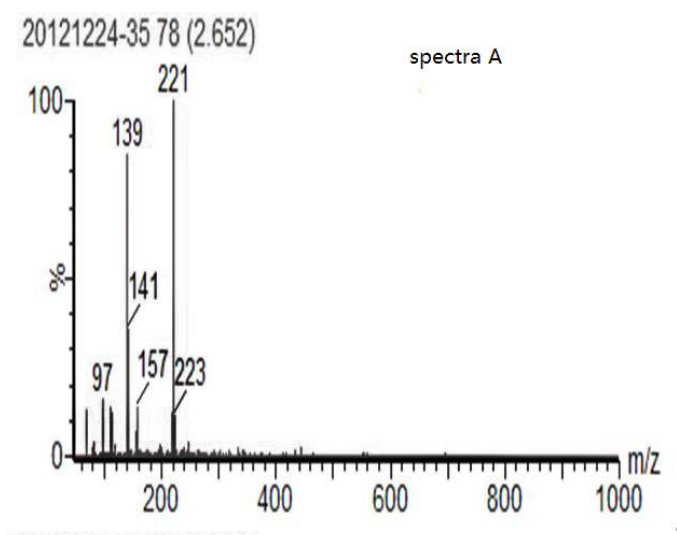

$20121224-35178(6.053)$
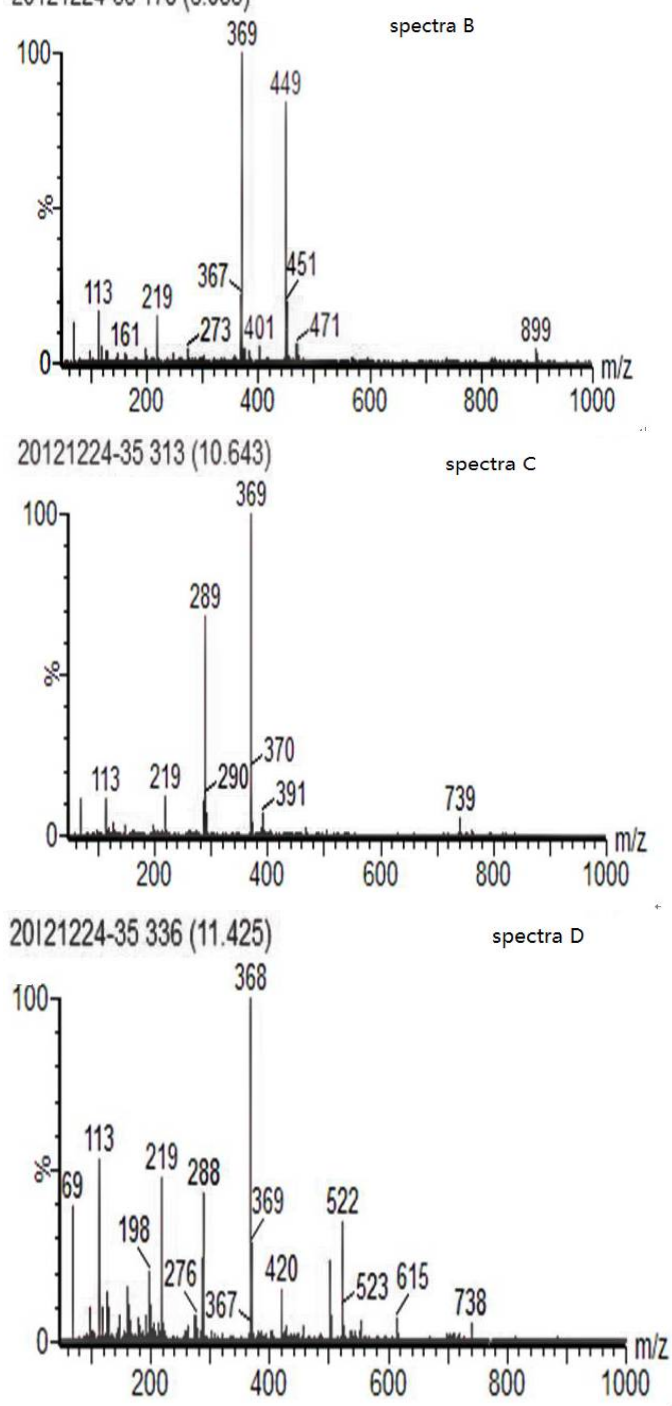

Figure 3: ESI mass spectra of enzymatic oxidation products of CA. From spectra A to D: peak 2, peak 8 , peak 22 , and peak 23

8, 22, and 23 generated under the same conditions after a $10 \mathrm{~min}$ reaction revealed obvious increases, suggesting that the substances from peaks $2,8,22$, and 23 were products of the enzymatic oxidation of CA. In addition, peak 9 was $\mathrm{CA}$ and revealed a decrease in CA content as the duration of the reaction was extended. Conversely, the substances from peaks 8,22 , and 23 exhibited obvious increases. The mass spectral analysis of these substances is shown in Figure 3.

The retention times of the CA enzymatic oxidation products in peaks 2,8 , and 22 were $2.65,6.05$, and $10.64 \mathrm{~min}$, respectively. The abundant ion with $\mathrm{m} / \mathrm{z} 369$ in the MS spectrum corresponding to peak 22 indicated that the peak represented hydroxyl CA (molecular mass 370) with the loss of an $\mathrm{H}^{+}$ion due to ionization. In addition, the approximately double molecular mass of the $\mathrm{m} / \mathrm{z} 739$ ion suggested that the substance from this peak was the monomer of hydroxyl CA. The $\mathrm{m} / \mathrm{z}$ peaks in the spectrum corresponding to peak 8 (6.05 min retention time) revealed similarities to the $\mathrm{m} / \mathrm{z}$ in the spectrum corresponding to peak 22. Consequently, we concluded that the products represented by peaks 8 and 22 were hydroxyl derivatives of CA. The structural characteristics of peak 2 were difficult to discern due to its small molecular mass, which indicated that it might not be an oxidation product of CA. In addition, due to the existence of characteristic ions with $\mathrm{m} / \mathrm{z} 368$ and 738 in the mass spectrum corresponding to peak 23 , this fraction was believed to be p-quinone of CA because the peak with $\mathrm{m} / \mathrm{z} 738$ was nearly double that of $\mathrm{m} / \mathrm{z} 368$.

\section{Oxidation pathway of CA in honeysuckle}

Based on the results of the LC-MS analysis of the CA oxidation model system, we proposed a schematic diagram to describe the CA oxidation pathway (Figure 4).

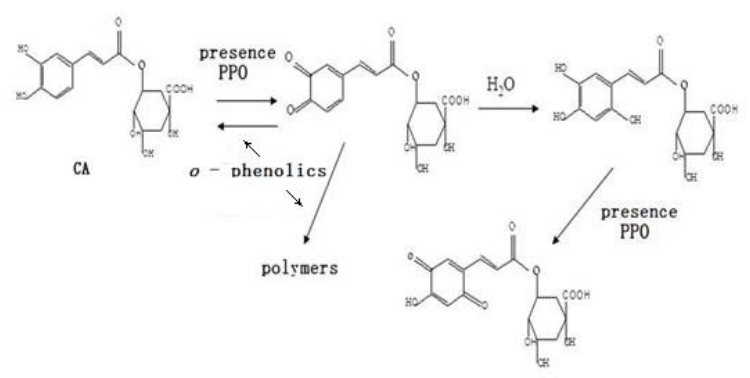

Figure 4: $C A$ oxidation pathway in the mimic enzymatic oxidation system

\section{DISCUSSION}

In the simulated enzymatic oxidation system, hydroxyl CA, p-quinone derivatives, and oquinone derivatives of $\mathrm{CA}$ were detected, indicating that $\mathrm{CA}$ generates hydroxyl $\mathrm{CA}$ in an enzymatic oxidation system. However, the o- 
quinone monomer of CA was also detected, which was most likely due to its instability and ready participation in the oxidation reaction and production of o-quinone and p-quinone CA derivatives. Nonetheless, despite the detection of the o-quinone intermediate monomer reaction during the enzymatic oxidation, the oxidation process and CA enzymatic oxidation reaction were consistent.

\section{CONCLUSION}

The presence of enzymatic oxidation products indicate that polymerization process was involved in the enzymatic oxidation of CA. Quinones are oxidized derivatives of aromatic compounds that are readily made from phenolic compounds, and phenolic compounds in plantbased foods are important factors in enzymatic browning. Therefore, the results of this study provide an effective strategy for preserving the quality of honeysuckle buds and other fresh agricultural products.

\section{ACKNOWLEDGEMENT}

The authors would like to thank Mrs Yin and Ms Hao for collecting honeysuckle buds from the Planting Base. The authors also thank Mr. Zhang for assistance with language editing.

\section{REFERENCES}

1. Shi W, Shi RB. Chinese Medicinal Honeysuckle Resources, Chemical Composition, and
Pharmacological Research Progress. Chinese Pharm J 1999; 34(11): 724.

2. Wu SB, Long CL, Kennelly EJ. Metabolite profiling of jaboticaba (Myrciaria cauliflora) and other dark-colored fruit juices. J Agric Food Chem 2012; 60: 7513-7525.

3. Jing $Y M$, Zhang $Z Q$, Joyce $D C$, Ketsa S. Postharvest biology and handling of longan fruit (Dimocarpus longan Lour.). Postharvest Biol Tec 2002; 26(3): 241-252.

4. Kader F, Haluk JP, Nicolas JP. Anthocyanin degration in oxidizing grape musts. J Sci Food Agric 1994; 46: 30603065.

5. Amiot MJ, Fleuriet A, Cheynier V. Phytochemistry of Fruits and Vegetables. Oxford University Press, New York, USA. 1997; pp 51-85.

6. Sheptovitsky YG, Brudvig GW. Isolation and characterization of spinach photosystem II membraneassociated catalase and polyphenol oxidase. Biochem 1996; 35: 16255-16263.

7. Hou SS, Luo L. Mechanism of honeysuckle color degeneration in hot air drying. Acad. Period. Farm $P P$ 2010; 10: 63-65.

8. Robards K, Prenzler PD, Prenzler G, et al. Phenolic compounds and their role in oxidative processes in fruits. Food Chem 1999; 66: 401-436.

9. Arzu A, Vural G. Partial purification and characterization of polyphenoloxidase from durum wheat. $J$ Cereal Sci 2012; 50: 300-304.

10. Gisela PO, Alicia OM, Lidia DÁ. Purification and partial biochemical characterization of polyphenol oxidase from mamey (Pouteria sapota). Phytochem Anal 2011; 72 : 82-88.

11. Eswari A, Rajendran L. Analytical expressions pertaining to the concentration of catechol, o-quinone and current at PPO-modified microcylinder biosensor for diffusionkinetic model. J Electroanal Chem 2011; 660: 200-208. 